\title{
Head-to-head comparison of single-breath and tidal-breath exhaled nitric oxide measurements
}

\author{
Sara Torretta ${ }^{1}$, Anna Bossi ${ }^{2}$, Alessandra Brevi' ${ }^{1}$, Werner Garavello ${ }^{3}$, Elisabetta lofrida', Rosaria Lorusso' and Lorenzo Pignataro
}

BACKGROUND: Exhaled nitric oxide (eNO) is an endogenous gas involved in airway pathophysiology and is determined in orally exhaled air by various techniques. However, traditional single-breath technique $\left(\mathrm{eNO}_{\mathrm{SB}}\right)$ requires active cooperation and is not always easily practicable (especially in young children); simpler techniques including tidal breathing measurements $\left(e \mathrm{NO}_{\mathrm{TB}}\right)$ are not standardized. The aim of this study was to evaluate the possible correlation and correspondence between eNO $\mathrm{NB}_{\mathrm{SB}}$ and $\mathrm{eNO}_{\mathrm{TB}}$ and the impact of potential confounders in children with chronic adenotonsillar disease.

METHODS: Eighty-six children (mean age $8.7 \pm 3.2$ y) underwent eNO assessment by means of eNO $\mathrm{SB}_{\mathrm{SB}}$ and eNO $\mathrm{NB}_{\mathrm{TB}}$. The correlation among $\mathrm{eNO}_{\mathrm{TB}^{\prime}} \mathrm{eNO}_{\mathrm{SB}^{\prime}}$ and other potential confounders (i.e., gender, age, weight, height, BMI, and passive smoking exposure) were studied.

RESULTS: The analyses showed a poor correspondence between $\mathrm{eNO}_{\mathrm{SB}}$ and $\mathrm{eNO}_{\mathrm{TB}}$, with the latter underestimating $(P<$ 0.001) mean eNO values: 6.4 parts per billion (ppb) $(95 \%$ confidence interval (Cl): 8.4-11.4 ppb) vs. 9.8 ppb (95\% Cl: 5.6-7.3 $\mathrm{ppb})$. A greater correlation was found between $\mathrm{eNO}_{\mathrm{SB}}$ and eNO $\mathrm{TB}_{\mathrm{T}}$ in children younger than $6 \mathrm{y}$. Only eNO $\mathrm{SB}_{\mathrm{SB}}$ and age predicted eNO $\mathrm{NB}_{\mathrm{TB}}\left(R^{2}=43.6 \%\right)$.

CONCLUSION: $\mathrm{eNO}_{\mathrm{TB}}$ is not a good predictor of eNO $\mathrm{NO}_{\mathrm{SB}}$ in children. Constant-flow eNO $\mathrm{NB}_{\mathrm{SB}}$ is the technique of choice for eNO assessment in young children.

$\mathbf{N}$ itric oxide (NO) is an endogenous gas involved in airway pathophysiology and is produced in the upper and lower airways as a result of the NO synthase (NOS) catalysis of $\mathrm{L}$-arginine. It can be determined in orally exhaled and nasal air by means of various noninvasive techniques $(1,2)$.

Orally exhaled NO (eNO) is mainly involved in important phlogistic pathways in the lower airways and can be considered a marker of inflammation in asthmatic patients (3). Increased eNO levels have been found in patients with allergic rhinitis (4) and upper respiratory tract viral infections (5) and reduced eNO levels have been found in patients with cystic fibrosis and primary ciliary dyskinesia (6). Furthermore, NO pathways are thought to be involved in the pathogenesis of chronic adenoidal disease because high nasal NO levels have been found in children with adenoidal hypertrophy (7), whereas contrasting results have been found in children with chronic tonsillar disease $(8,9)$.

The assessment of eNO is not used in routine pediatric practice because it is not always easily practicable to follow the international guidelines $(1,2)$. Traditional eNO measurement of oral exhalation against resistance (the single-breath technique, $\mathrm{eNO}_{\mathrm{SB}}$ ) is considered the standard procedure by the American Thoracic Society (2) because it has several advantages: a constant flow is maintained, which is useful because eNO is a flow-dependent variable (10); exhalation from total lung capacity is important because the degree of lung expansion affects eNO values measured at the same flow rate (10); and contamination with nasal NO is avoided because of the induced velum closure when exhaling against resistance (10).

However, correct $\mathrm{eNO}_{\mathrm{SB}}$ performance requires the active cooperation of patients, which is not always easily achieved, especially in the case of young children (1). For this reason, simpler but less standardized techniques have been introduced in an attempt to overcome the poor compliance of children, including tidal-breath eNO measurements $\left(\mathrm{eNO}_{\mathrm{TB}}\right)$ with or without flow control, and offline reservoir sampling (1,11-13). Unfortunately, these do not provide accurate data because they have some methodological drawbacks, such as the use of uncontrolled expiratory flow and nasal NO contamination (1). Furthermore, previous studies (11-13) of eNO levels assessed by means of $\mathrm{eNO}_{\mathrm{SB}}$ and $\mathrm{eNO}_{\mathrm{TB}}$ with or without the use of sampling bags in infants or children with bronchopulmonary disease have yielded conflicting results.

The aim of this study was to evaluate the possible correlation and correspondence between $\mathrm{eNO}_{\mathrm{SB}}$ and $\mathrm{eNO}_{\mathrm{TB}}$ measurements and the impact of potential confounders in children with chronic adenotonsillar disease.

\section{RESULTS}

As shown in Figure 1, 184 children were considered eligible for enrollment, but the final analyses were based on the measurements of 86 children ( $53.5 \%$ males; mean age $8.7 \pm 3.2 \mathrm{y}$ ) whose main characteristics are summarized in Table 1. 

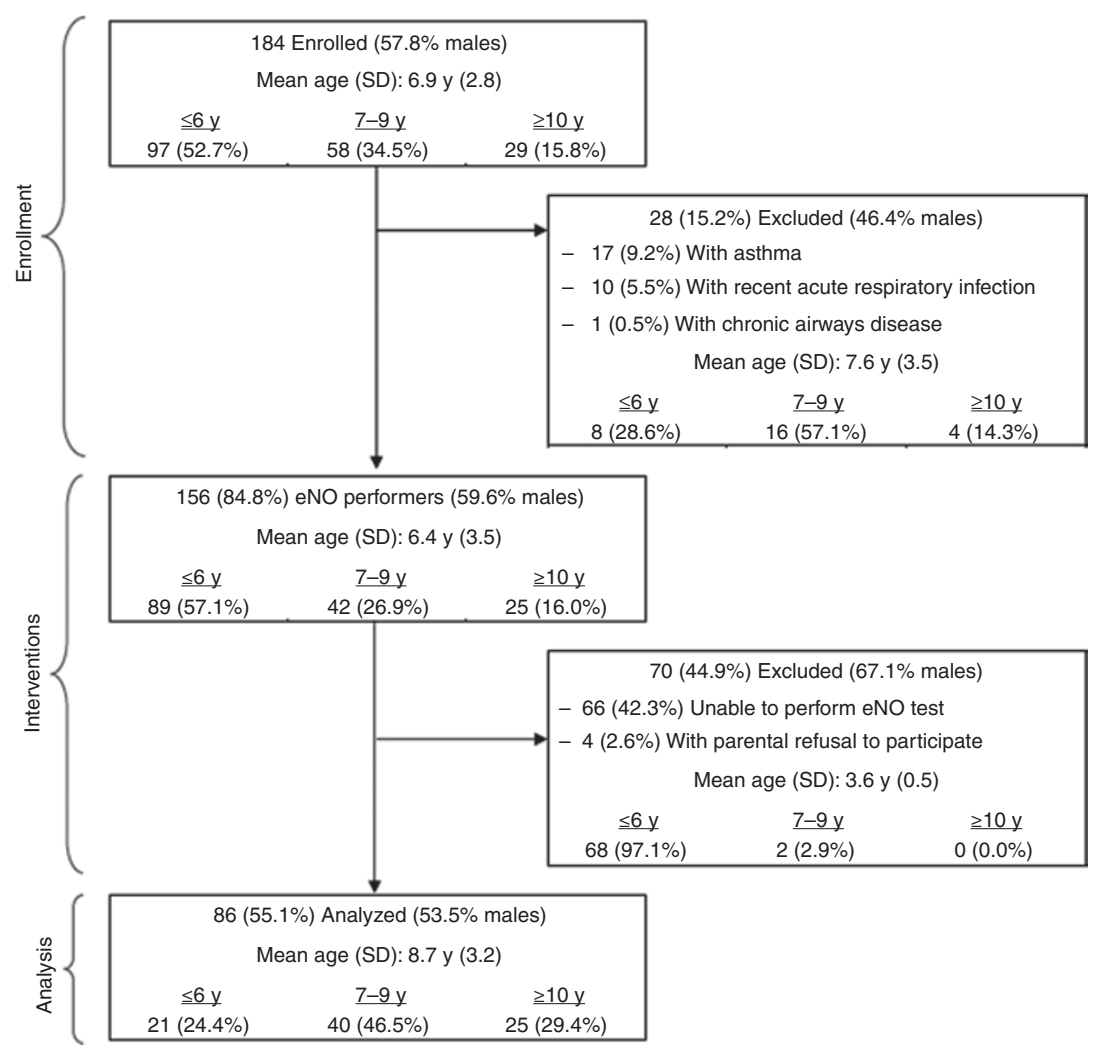

Figure 1. Study flowchart. eNO, exhaled nitric oxide.

Table 1. Main characteristics of the 86 pediatric patients

\begin{tabular}{|c|c|c|}
\hline Variable & $n$ & $\%$ \\
\hline \multicolumn{3}{|l|}{ Gender } \\
\hline Male & 46 & 53.5 \\
\hline Female & 40 & 46.5 \\
\hline \multicolumn{3}{|l|}{ Age (y) } \\
\hline$\leq 6$ & 21 & 24.4 \\
\hline $7-9$ & 40 & 46.5 \\
\hline$\geq 10$ & 25 & 29.1 \\
\hline \multicolumn{3}{|c|}{ Passive smoking exposure } \\
\hline No & 68 & 79.1 \\
\hline \multirow[t]{2}{*}{ Yes } & 18 & 20.9 \\
\hline & Median & $\mathrm{Q}_{1}-\mathrm{Q}_{3}$ \\
\hline Weight (kg) & 27 & $21.3-39.0$ \\
\hline Height (cm) & 130 & $116.0-142.0$ \\
\hline \multicolumn{3}{|l|}{ BMI } \\
\hline$<-1 \mathrm{SD}$ & 25 & 29.1 \\
\hline$-1 \mathrm{SD}$ to $+1 \mathrm{SD}$ & 40 & 46.5 \\
\hline \multirow[t]{2}{*}{$>+1 \mathrm{SD}$} & 21 & 24.4 \\
\hline & Mean & $\mathrm{Cl}_{95 \%}$ \\
\hline $\mathrm{eNO}_{\mathrm{SB}}$ & 9.8 & $5.6-7.3$ \\
\hline $\mathrm{eNO}_{\mathrm{TB}}$ & 6.4 & $8.4-11.4$ \\
\hline
\end{tabular}

$\mathrm{Cl}_{95 \% \%} 95 \%$ confidence interval; $\mathrm{eNO}_{\mathrm{SB}^{\prime}}$ exhaled nasal nitric oxide measured with singlebreath technique; $\mathrm{eNO}_{\mathrm{TR}^{\prime}}$ exhaled nasal nitric oxide measured with tidal breathing technique; Q1, first quartile; Q3, third quartile.
Although the coefficient of variation was the same for both techniques (33.4\%), the geometric mean of $\mathrm{eNO}_{\text {Тв }}$ was significantly less than that of $\mathrm{eNO}_{\mathrm{SB}}: 6.4 \mathrm{ppb}(95 \%$ confidence interval: (CI) $8.4-11.4)$ vs. $9.8 \mathrm{ppb}(95 \% \mathrm{CI}: 5.6-7.3)(P<0.001)$. The underestimates of the $\mathrm{eNO}_{\mathrm{TB}}$ values in comparison with the $\mathrm{eNO}_{\mathrm{SB}}$ values are shown in Figure 2: $76 \%$ of the $\mathrm{eNO}_{\mathrm{TB}}$ values were under the bisectrix indicating perfect correspondence.

Only $\mathrm{eNO}_{\mathrm{SB}}$ and age were predictors of $\mathrm{eNO}_{\mathrm{TB}}$; the $R^{2}$ of $43.6 \%$ suggests that the model explains slightly less than half of the variability of $\mathrm{eNO}_{\mathrm{TB}}$. The scatter plots of the values predicted by the final equations, $\ln \left(\mathrm{eNO}_{\mathrm{TB}}\right)=\mathrm{f}\left[\right.$ age, $\left.\ln \left(\mathrm{eNO}_{\mathrm{SB}}\right)\right]$ vs. $\ln \left(\mathrm{eNO}_{\mathrm{SB}}\right)$ and residuals vs. $\ln \left(\mathrm{eNO}_{\mathrm{SB}}\right)$, are shown in Figure 3 and confirm the underestimated $\mathrm{eNO}_{\mathrm{TB}}$ values. They also show that the correlation between $\mathrm{eNO}_{\mathrm{SB}}$ and $\mathrm{eNO}_{\mathrm{TB}}$ values was higher in children younger than $6 \mathrm{y}$ and that the discrepancy between the two techniques increased with age (Figure 4).

However, the differences between $\mathrm{eNO}_{\mathrm{SB}}$ and $\mathrm{eNO}_{\mathrm{TB}}$ led to the misclassification of normal and pathological values in every age class. When $\mathrm{eNO}$ was assessed using the tidal breathing technique, $\sim 50 \%$ of the patients whose $\mathrm{eNO}_{\mathrm{SB}}$ values were in the normal range would have been considered pathological cases, and $19 \%$ of those whose $\mathrm{eNO}_{\mathrm{SB}}$ values were out of the normal range would have been considered normal. As a matter of fact, correct responses occurred in $55.8 \%$ of cases when the population was considered as a whole; when considered by age class, correct responses occurred in $52.4 \%$ of the children aged $4-7 \mathrm{y}$, in $52.5 \%$ of those aged $8-13 \mathrm{y}$, and in $64.0 \%$ of those aged $14-17 \mathrm{y}$. 


\section{DISCUSSION}

The assessment of eNO levels could be very useful in clinical practice for diagnostic purposes and for monitoring respiratory diseases such as airway inflammation $(3,6,14)$, adenoidal disease (7), and rhino-sinusitis (15). The international guidelines recommend $\mathrm{NO}_{\mathrm{SB}}$ as the "gold standard" technique (1) on the grounds of its accuracy and reproducibility (10). However, the active cooperation required to achieve the lasting expiratory force necessary to perform the test correctly makes it impossible in some patients, especially preschool children (16), as was found in $\sim 45 \%$ of our enrolled patients who had a mean age of $3.6 \pm 0.5 \mathrm{y}$.

Practical difficulties in assessing $\mathrm{eNO}_{\mathrm{SB}}$ in pediatric populations have been previously reported by other investigators $(11,17)$, including Jöbsis et al. (11) who found that $29 \%$ of 101 children with a mean age of $11.7 \mathrm{y}$ were unable to perform the test. These difficulties have led to the introduction of simpler

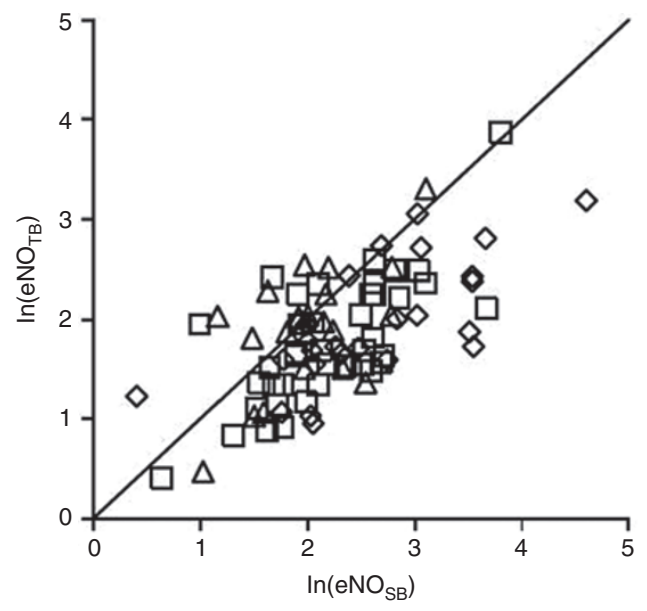

Figure 2. Relationship between logarithm of exhaled nasal nitric oxide (eNO) measured with tidal-breath (TB) and single-breath (SB) techniques. Triangles, children $\leq 6 \mathrm{y}$; squares, children $7-9 \mathrm{y}$; diamonds, children $\geq 10 \mathrm{y}$. but less standardized means of assessing eNO, including $\mathrm{eNO}_{\mathrm{TB}}$ measurements $(11,13)$, but these have the disadvantages of variable expiratory flow and the impossibility of excluding nasal NO $(1,18)$.

We therefore evaluated the correlation and correspondence between $\mathrm{eNO}_{\mathrm{TB}}$ and $\mathrm{eNO}_{\mathrm{SB}}$ values in children, also considering the other variables known to influence eNO levels, such as gender, age, height, weight, BMI, and passive smoking exposure (2), in order to assess the possibility of using $\mathrm{eNO}_{\mathrm{TB}}$ in pediatric clinical practice.

As expected (on the basis of the fact that both techniques evaluate eNO levels), our findings showed a certain correlation (good correlation occurred when $\mathrm{eNO}_{\mathrm{SB}}$ and $\mathrm{eNO}_{\mathrm{TB}}$ systematically varied together) between $\mathrm{eNO}_{\mathrm{SB}}$ and $\mathrm{eNO}_{\mathrm{TB}}$ in 86 children with chronic adenotonsillar disease $(70 \%$ of whom were younger than $9 \mathrm{y}$ ).

However, our results showed that a good correspondence (good correspondence occurred when $\mathrm{eNO}_{\mathrm{SB}}$ and $\mathrm{eNO}_{\mathrm{TB}}$ gave the same response) between the eNO measurements was obtained neither when the population was analyzed as a whole nor when it was analyzed by age class.

In comparison with $\mathrm{eNO}_{\mathrm{SB}}, \mathrm{eNO}_{\mathrm{TB}}$ systematically underestimated eNO values, as also shown by the statistically significant difference in their mean values of 9.8 and $6.4 \mathrm{ppb}$, respectively. Furthermore, the underestimated $\mathrm{eNO}_{\text {Тв }}$ values seem to be more pronounced at higher values (see Figure 3 ), which is in line with the findings of Franklin et al. (12). The systematic underestimation of eNO values by $\mathrm{eNO}_{\mathrm{TB}}$ is not easily interpreted and should be considered cautiously. Contamination with nasal NO, which is increased in children with adenoidal disease (7), should theoretically increase rather than decrease the eNO levels measured during tidal breathing. However, it must be remembered that eNO levels vary with flow (10), and the multiple respirations without flow control during $\mathrm{eNO}_{\mathrm{TB}}$ lead to considerable differences between the levels determined by the two techniques.
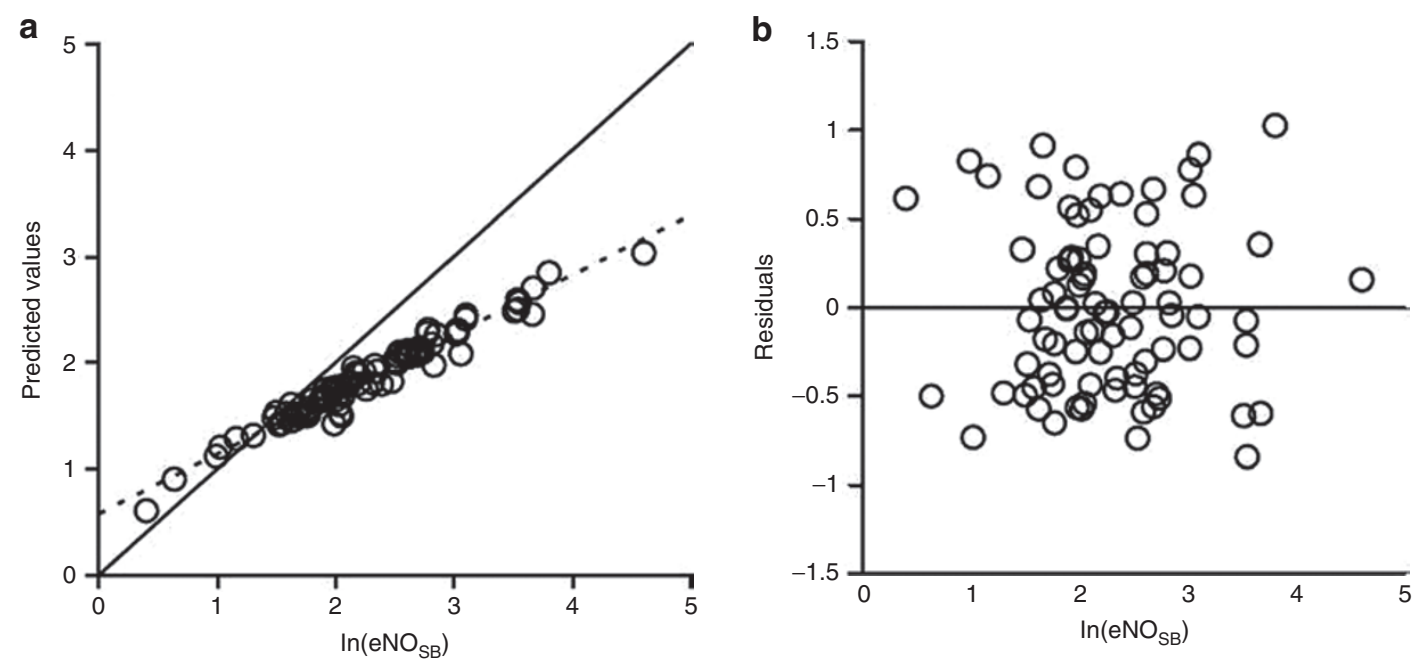

Figure 3. Relationship between predicted $\mathrm{NNO}_{\mathrm{TB}}$ and observed $\mathrm{eNO}_{\mathrm{SB}}$ values. (a) Scatter plots of the values predicted by the final equation $\ln \left(\mathrm{eNO} \mathrm{TB}_{\mathrm{TB}}\right)=\mathrm{f}$ $\left(\right.$ age, $\ln \left(\mathrm{eNO}_{\mathrm{SB}}\right)$ vs. $\ln \left(\mathrm{eNO}_{\mathrm{SB}}\right)$. (b) Scatter plots of the residuals from the final equation $\ln \left(\mathrm{eNO}_{\mathrm{TB}}\right)=\mathrm{f}\left(\right.$ age, $\left.\ln \left(\mathrm{eNO} \mathrm{SB}_{\mathrm{SB}}\right)\right) \mathrm{vs}$. In $\left(\mathrm{eNO} \mathrm{SB}_{\mathrm{SB}}\right.$. eNO, exhaled nitric oxide; $\mathrm{SB}$, single breath; TB, tidal breath. 
a

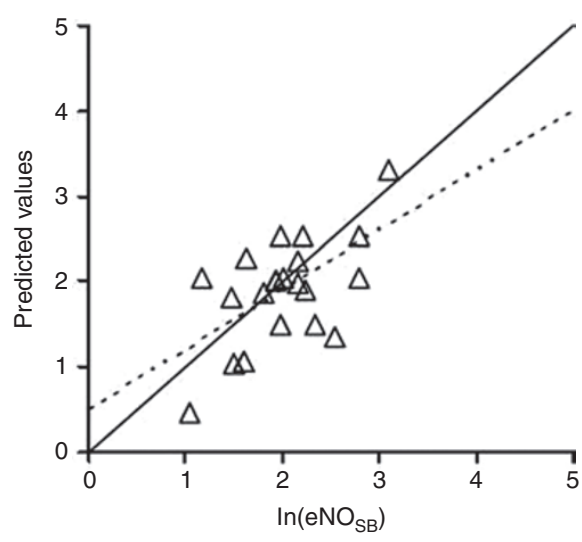

b

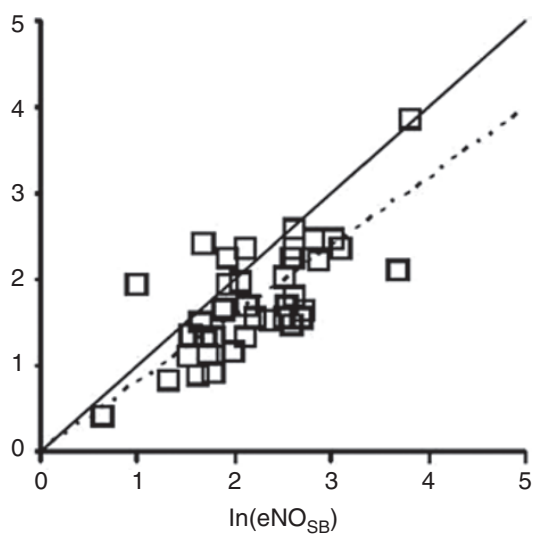

C

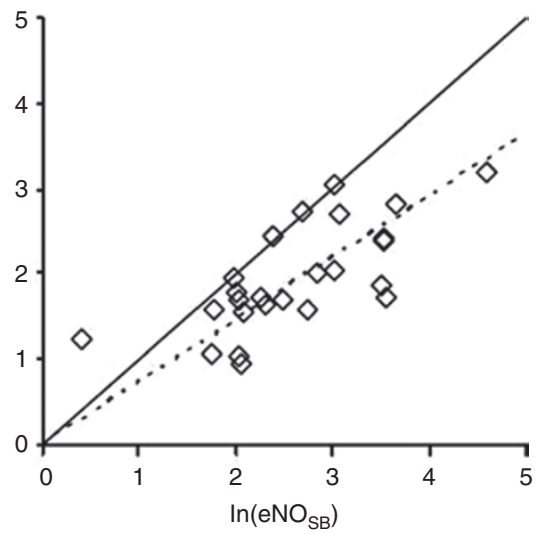

Figure 4. Scatter plots of the values predicted by the final equation $\ln \left(\mathrm{eNO}_{\mathrm{TB}}\right)=\mathrm{f}\left(\mathrm{age}, \ln \left(\mathrm{eNO}_{\mathrm{SB}}\right)\right) \mathrm{vs}$. $\ln \left(\mathrm{eNO} \mathrm{SB}_{\mathrm{SB}}\right)$. (a) Triangles, children $\leq 6 \mathrm{y}(n=21)$. $\ln \left(\mathrm{eNO}_{\mathrm{TB}}\right)=0.93 \times \ln \left(\mathrm{eNO}_{\mathrm{SB}}\right)\left(\mathrm{Cl}_{90 \%}(\beta)=(0.86-1.00)\right)$. (b) Squares, children 7-9 y $(n=40)$. $\ln \left(\mathrm{eNO}_{\mathrm{TB}}\right)=0.79 \times \ln \left(\mathrm{eNO}_{\mathrm{SB}}\right)\left(\mathrm{Cl}_{90 \%}(\beta)=(0.75-0.83)\right)$. (c) Diamonds, children $\geq 10$ y $(n=25)$. $\ln \left(\mathrm{eNO}_{\mathrm{TB}}\right)=0.73 \times \ln \left(\mathrm{eNO}_{\mathrm{SB}}\right)\left(\mathrm{Cl}_{90 \%}(\beta)=(0.68-0.77)\right)$. Line, bisector; dotted line, interpolating straight line. $\mathrm{Cl}_{90 \%}, 90 \%$ confidence interval; eNO, exhaled nitric oxide; SB, single breath; TB, tidal breath.

Our results add to the debate concerning the conflicting results from previous studies comparing eNO levels as measured by means of $\mathrm{eNO}_{\mathrm{SB}}$ and $\mathrm{eNO}_{\mathrm{TB}}$ in pediatric patients with lower airway diseases $(11,19)$. Jöbsis et al. (11) and Franklin et al. (12) found that agreement between $\mathrm{eNO}_{\mathrm{SB}}$ and $\mathrm{eNO}_{\mathrm{TB}}$ was poor in asthmatic children and in infants with recurrent wheeze, recurrent cough, or no respiratory symptoms. Our findings confirm this in pediatric patients with chronic upper airway disease. To the best of our knowledge, only Daniel et al. (13) did not find any significant difference between $\mathrm{eNO}_{\mathrm{SB}}$ and $\mathrm{eNO}_{\mathrm{TB}}$ (using a facemask) in a small case series of 11 children aged 8-12 y.

Among all the variables assessed, only age significantly changed the correlation between $\mathrm{eNO}_{\mathrm{SB}}$ and $\mathrm{eNO}_{\mathrm{TB}}$. In particular, the greatest discrepancy between the $\mathrm{eNO}_{\mathrm{SB}}$ and $\mathrm{eNO}_{\mathrm{TB}}$ values was observed in children older than $6 \mathrm{y}$, whose $\mathrm{eNO}_{\mathrm{SB}}$ values were generally higher than their $\mathrm{eNO}_{\mathrm{TB}}$ values (Figure 4). It can be speculated that nasal contamination during $\mathrm{eNO}_{\text {тв }}$ is more significant in younger children because they are more frequently affected by adenoidal disease (20), which is responsible for increased nasal NO levels (7). This may explain the reduced difference between $\mathrm{eNO}_{\mathrm{SB}}$ and $\mathrm{eNO}_{\mathrm{TB}}$ values in children younger than $6 \mathrm{y}$.

In conclusion, our results showed that although there was a certain correlation between $\mathrm{eNO}_{\mathrm{SB}}$ and $\mathrm{eNO}_{\mathrm{TB}}, \mathrm{eNO}_{\mathrm{TB}}$ cannot be considered a good predictor of $\mathrm{eNO}_{\mathrm{SB}}$ in children with chronic adenotonsillar disease on the basis of its poor correspondence even when it was adjusted for age. On the basis of our results, and given the dependence of eNO levels on expiratory flow, constantflow $\mathrm{eNO}_{\mathrm{SB}}$ should be considered the technique of choice for $\mathrm{eNO}$ assessment in young children with chronic upper airway disease, and clinicians should question the reliability of $\mathrm{eNO}_{\mathrm{TB}}$.

\section{METHODS}

\section{Patients and Setting}

The study involved 184 consecutive children aged 3-17 y, who attended the Otorhinolaryngological Unit of the University of Milan's Department of Clinical Sciences and Community Health between January 2008 and May 2009 because of chronic adenoidal and/or tonsillar disease. Chronic adenoiditis was defined as adenoidal hypertrophy (assessed by means of flexible nasopharyngeal endoscopy) with ongoing nasopharyngeal inflammation/infection (i.e., at least three episodes of acute adenoiditis requiring antibiotic therapy in a period of 6 mo or at least four episodes in the previous year) (21), persistent mucous secretion on the adenoidal surface, and/or persistent otitis media with effusion (persistent middle ear effusion for at least $3 \mathrm{mo}$, without any sign of concomitant acute inflammation) (22), and/or recurrent acute otitis media (i.e., a history of at least three documented episodes in the previous 6 mo or at least four in the previous year) (23). Chronic tonsillitis was defined as severe recurrent tonsillar infections (at least seven episodes of acute tonsillitis in the previous year, at least five episodes per year for 2 consecutive years, or at least three episodes per year for at least 3 consecutive years) (24).

Exclusion criteria were as follows: an inability to perform $\mathrm{eNO}_{\mathrm{SB}}$ or $\mathrm{eNO}_{\mathrm{TB}}$; allergic asthma or chronic airway diseases (25); acute respiratory infections during the previous $30 \mathrm{~d}$ and/or the administration of systemic antibiotics and/or steroids or other medications affecting the airways (e.g., inhaled steroids, nasal steroids, or decongestants) during the previous month; systemic diseases (e.g., cystic fibrosis, primary ciliary dyskinesia, and primary or secondary immunodeficiency) (21); and parental refusal to participate.

The protocol was approved by the University of Milan's Ethics Committee, and written informed consent was obtained from the children's parents or their legal guardians.

\section{Intervention}

Gender, age, weight $(\mathrm{W})$, height $(\mathrm{H})$, BMI (computed as $\mathrm{W}(\mathrm{kg}) / \mathrm{H}^{2}\left(\mathrm{~m}^{2}\right)$ ), and passive smoking exposure (defined as whether parental figures such as mother, father, stepfather, or mother's partner, and stepmother or father's partner smoked in the home every day or sometimes) (19) were recorded for each patient, and the children underwent $\mathrm{eNO}_{\mathrm{SB}}$ and $\mathrm{eNO}_{\mathrm{TB}}$ determinations by means of a dedicated chemiluminescence analyzer (CDL $88 \mathrm{sp}$, Ecomedics, Dürnten, Suisse). At the parent's discretion, the child was comfortably seated on a chair or on the parent's knee. The child was encouraged to breathe only through his/her mouth and to breathe quietly for some minutes so as to acclimatize. The $\mathrm{eNO}_{\mathrm{TB}}$ measurement was made first using an online method of tidal breathing: the child was asked to perform oral tidal breathing continuously through a disposable mouthpiece connected to the CDL 88 sp by means of a two-way valve. The exercise was repeated three times separated by at least $30 \mathrm{~s}$ of rest. The recorded $\mathrm{eNO}_{\mathrm{TB}}$ level, expressed in parts per billion ( $\mathrm{ppb}$ ), was the geometric mean of the three values obtained.

$\mathrm{eNO}_{\mathrm{SB}}$ measurement was made using an online, constant flow method in accordance with the international guidelines $(1,2)$. The child was encouraged to inhale NO-free air $(<5 \mathrm{ppb})$ orally for $2-3 \mathrm{~s}$ to total lung capacity from a disposable mouthpiece connected to the analyzer by means of a two-way valve and then to exhale orally for $>4 \mathrm{~s}$ without 
holding the breath at a constant flow rate $(50 \mathrm{ml} / \mathrm{s})$ through an expiratory resistance, targeting a mouth pressure of $10 \mathrm{~cm} \mathrm{H}_{2} \mathrm{O}$ in order to close the velum and avoid nasal contamination. The test ended with another oral inhalation through the CDL $88 \mathrm{sp}$. The children were helped to maintain a constant expiratory flow rate by means of a real-time visual aid, and $\mathrm{eNO}_{\mathrm{SB}}$ was computed when an $\mathrm{eNO}_{\mathrm{SB}}$ plateau of $>2 \mathrm{~s}$ could be identified during exhalation. The $\mathrm{eNO}_{\mathrm{SB}}$ level was recorded after three exhalations were repeated after intervals of $>30 \mathrm{~s}$. The analyzer was calibrated every 2 wk using certified 2,000 ppb calibration gas.

The correspondence between the $\mathrm{eNO}_{\mathrm{SB}}$ and $\mathrm{eNO}_{\mathrm{TB}}$ levels classifying patients as normal or pathological was assessed on the basis of published normal values for age classes, i.e., 5-8 ppb in children aged $4-7 \mathrm{y} ; 8-16 \mathrm{ppb}$ in children aged 8-13 y; and 10-13 ppb in children aged $14-17$ y $(26-30)$.

\section{Statistical Analysis}

Because the $\mathrm{eNO}_{\mathrm{SB}}$ and $\mathrm{eNO}_{\mathrm{TB}}$ values were not normally distributed, log-transformed data were used for the analyses. The $\mathrm{eNO}_{\mathrm{SB}}$ and $\mathrm{eNO}_{\mathrm{T}}$ data are given as geometric mean values with $95 \%$ CIs; the height and weight data as median values and interquartile ranges; and the other variables as frequencies (absolute numbers and percentages).

Multivariable linear regression models were used to examine the correlation among $\mathrm{eNO}_{\mathrm{TB}}$, $\mathrm{eNO}_{\mathrm{SB}}$, and the other potential confounders such as gender, age (continuous), height (continuous), weight (continuous), BMI, and passive smoking exposure. The goodness of fit of the models was evaluated using the coefficient of determination $\left(\mathrm{R}^{2}\right)$. A $P$ value of $<0.10$ was considered statistically significant. Data processing and all of the statistical analyses were performed by using the SAS software (version 9.1, SAS Institute, Cary, North Carolina).

\section{STATEMENT OF FINANCIAL SUPPORT}

No financial support from extramural sources was received for this study.

\section{REFERENCES}

1. Baraldi E, de Jongste JC; European Respiratory Society/American Thoracic Society (ERS/ATS) Task Force. Measurement of exhaled nitric oxide in children, 2001. Eur Respir J 2002;20:223-37.

2. American Thoracic Society, European Respiratory Society. ATS/ERS recommendations for standardized procedures for the online and offline measurement of exhaled lower respiratory nitric oxide and nasal nitric oxide, 2005. Am J Respir Crit Care Med 2005;171:912-30.

3. Kharitonov SA, Yates D, Robbins RA, Logan-Sinclair R, Shinebourne EA, Barnes PJ. Increased nitric oxide in exhaled air of asthmatic patients. Lancet 1994;343:133-5.

4. Martin U, Bryden K, Devoy M, Howarth P. Increased levels of exhaled nitric oxide during nasal and oral breathing in subjects with seasonal rhinitis. J Allergy Clin Immunol 1996;97:768-72.

5. Kharitonov SA, Yates D, Barnes PJ. Increased nitric oxide in exhaled air of normal human subjects with upper respiratory tract infections. Eur Respir J 1995;8:295-7.

6. Hofer M, Mueller L, Rechsteiner T, Benden C, Boehler A. Extended nitric oxide measurements in exhaled air of cystic fibrosis and healthy adults. Lung 2009;187:307-13.

7. Torretta S, Bossi A, Capaccio P, et al. Nasal nitric oxide in children with adenoidal hypertrophy: a preliminary study. Int J Pediatr Otorhinolaryngol 2010;74:689-93.

8. Torretta S, Marchisio P, Esposito S, et al. Exhaled nitric oxide levels in children with chronic adenotonsillar disease. Int J Immunopathol Pharmacol 2011;24:471-80.

9. Kasperska-Zajac A, Brzoza Z, Czecior E, Rogala B, Polok A, Namyslowski G. Elevated levels of exhaled nitric oxide in recurrent tonsillitis. Eur Respir J 2008;31:909-10.

10. Silkoff PE, McClean PA, Slutsky AS, et al. Marked flow-dependence of exhaled nitric oxide using a new technique to exclude nasal nitric oxide. Am J Respir Crit Care Med 1997;155:260-7.
11. Jöbsis Q, Schellekens SL, Kroesbergen A, Hop WC, de Jongste JC. Sampling of exhaled nitric oxide in children: end-expiratory plateau, balloon and tidal breathing methods compared. Eur Respir J 1999;13:1406-10.

12. Franklin PJ, Turner SW, Mutch RC, Stick SM. Comparison of singlebreath and tidal breathing exhaled nitric oxide levels in infants. Eur Respir J 2004;23:369-72.

13. Daniel PF, Klug B, Valerius NH. Measurement of exhaled nitric oxide in young children during tidal breathing through a facemask. Pediatr Allergy Immunol 2005;16:248-53.

14. Scadding G, Scadding GK. Update on the use of nitric oxide as a noninvasive measure of airways inflammation. Rhinology 2009;47:115-20.

15. Carraro S, Cutrone C, Cardarelli C, Zanconato S, Baraldi E. Clinical application of nasal nitric oxide measurement. Int J Immunopathol Pharmacol 2010;23:Suppl 1:50-2.

16. Kissoon N, Duckworth LJ, Blake KV, Murphy SP, Taylor CL, Silkoff PE. $\mathrm{FE}(\mathrm{NO})$ : relationship to exhalation rates and online versus bag collection in healthy adolescents. Am J Respir Crit Care Med 2000;162(2 Pt 1): $539-45$.

17. Canady RG, Platts-Mills T, Murphy A, Johannesen R, Gaston B. Vital capacity reservoir and online measurement of childhood nitrosopnea are linearly related. Clinical implications. Am J Respir Crit Care Med 1999;159:311-4.

18. Franklin PJ, Turner SW, Mutch RC, Stick SM. Measuring exhaled nitric oxide in infants during tidal breathing: methodological issues. Pediatr Pulmonol 2004;37:24-30.

19. Holliday JC, Moore GF, Moore LA. Changes in child exposure to secondhand smoke after implementation of smoke-free legislation in Wales: a repeated cross-sectional study. BMC Public Health 2009;9:430.

20. Cassano P, Gelardi M, Cassano M, Fiorella ML, Fiorella R. Adenoid tissue rhinopharyngeal obstruction grading based on fiberendoscopic findings: a novel approach to therapeutic management. Int J Pediatr Otorhinolaryngol 2003;67:1303-9.

21. Marseglia GL, Poddighe D, Caimmi D, et al. Role of adenoids and adenoiditis in children with allergy and otitis media. Curr Allergy Asthma Rep 2009;9:460-4

22. American Academy of Pediatrics. Subcommittee on management of otitis media with effusion. Otitis media with effusion. Pediatrics 2004;113:1412-29.

23. American Academy of Pediatrics. Subcommittee on management of acute otitis media. Diagnosis and management of acute otitis media. Pediatrics 2004;113:1451-65.

24. Paradise JL, Bluestone CD, Bachman RZ, et al. Efficacy of tonsillectomy for recurrent throat infection in severely affected children. Results of parallel randomized and nonrandomized clinical trials. N Engl J Med 1984;310:674-83.

25. Kharitonov SA, Rajakulasingam K, O’Connor B, Durham SR, Barnes PJ Nasal nitric oxide is increased in patients with asthma and allergic rhinitis and may be modulated by nasal glucocorticoids. J Allergy Clin Immunol 1997;99(1 Pt 1):58-64.

26. Franklin PJ, Taplin R, Stick SM. A community study of exhaled nitric oxide in healthy children. Am J Respir Crit Care Med 1999;159:69-73.

27. Kharitonov SA, Gonio F, Kelly C, Meah S, Barnes PJ. Reproducibility of exhaled nitric oxide measurements in healthy and asthmatic adults and children. Eur Respir J 2003;21:433-8.

28. Buchvald F, Baraldi E, Carraro S, et al. Measurements of exhaled nitric oxide in healthy subjects age 4 to 17 years. J Allergy Clin Immunol 2005;115:1130-6.

29. Malmberg LP, Petäys T, Haahtela T, et al. Exhaled nitric oxide in healthy nonatopic school-age children: determinants and height-adjusted reference values. Pediatr Pulmonol 2006;41:635-42.

30. Kovesi T, Kulka R, Dales R. Exhaled nitric oxide concentration is affected by age, height, and race in healthy 9 - to 12 -year-old children. Chest 2008;133:169-75. 